\title{
ARTICULAÇÃO TEMPOROMANDIBULAR - ASPECTOS NORMAIS E DESLOCAMENTOS DE DISCO: IMAGEM POR RESSONÂNCIA MAGNÉTICA*
}

\author{
Ana Carolina Araújo Ramos ${ }^{1}$, Viviane Almeida Sarmento ${ }^{2}$, Paulo Sérgio Flores Campos ${ }^{3}$, \\ Maria Olívia Dias Gonzalez ${ }^{4}$
}

Resumo 0 deslocamento de disco da articulação temporomandibular tem sido definido como uma relação anormal do disco articular com o côndilo mandibular, fossa e eminência articulares. Os deslocamentos de disco podem estar presentes sem interferir com a função articular a curto prazo. A ressonância magnética tem sido o exame de imagem de primeira escolha para o diagnóstico das anormalidades de tecido mole da articulação temporomandibular, uma vez que apresenta alta acurácia na determinação da posição do disco articular. 0 objetivo deste trabalho é apresentar uma revisão de literatura, demonstrando os aspectos normais e os diferentes tipos de deslocamentos de disco desta articulação e o seu diagnóstico por imagem, destacando o papel do exame por ressonância magnética.

Unitermos: Articulação temporomandibular; Imagem por ressonância magnética; Diagnóstico.

Abstract Temporomandibular joint - normal features and disc displacements: magnetic resonance imaging.

Disc displacement of the temporomandibular joint has been defined as an abnormal relationship between the articular disc and the mandibular condyle, fossa and articular eminence. Disc displacements may occur without immediate interference in the function of the joint. Magnetic resonance imaging shows high diagnostic accuracy in the determination of articular disc position and has been indicated as the diagnostic method of choice for soft tissue abnormalities of the temporomandibular joint. The aim of this study is to review the literature including the normal features and different types of disc displacement of the temporomandibular joint as well as the imaging findings, emphasizing the role of magnetic resonance imaging. Key words: Temporomandibular joint; Magnetic resonance imaging; Diagnosis.

\section{INTRODUÇÃO}

A articulação temporomandibular (ATM), classificada como a mais complexa do organismo humano ${ }^{(1)}$, pode ser acometida pelas mesmas doenças e desordens que afetam outras articulações do sistema músculo-esquelético, como os deslocamentos de disco, doenças articulares degenerativas (osteoartrite), artrites inflamatórias e sinovites.

* Trabalho realizado na Clínica Delfin Médica e Odontológica e na Faculdade de Odontologia da Universidade Federal da Bahia (FOUFBA), Salvador, BA.

1. Mestre em Odontologia e Especialista em Radiologia Odontológica pela FOUFBA, Bolsista da Fundação de Amparo à Pesquisa do Estado da Bahia (Fapesb).

2. Doutora em Estomatologia Clínica pela Pontifícia Universidade Católica do Rio Grande do Sul (PUC-RS), Mestre em Odontologia pela FOUFBA, Professora Adjunta da FOUFBA.

3. Doutor em Diagnóstico Bucal pela Faculdade de Odontologia da Universidade de São Paulo (FOUSP), Mestre em Odontologia pela FOUFBA, Professor Adjunto da FOUFBA.

4. Especialista em Radiologia Odontológica pela FOUFBA

Endereço para correspondência: Dra. Ana Carolina Araújo Ramos. Rua Alameda dos Jasmins, 200, ap. 1001B, Cidade Jardim. Salvador, BA, 40280-620. E-mail: ana_carolinaramos@ hotmail.com

Recebido para publicação em 20/3/2003. Aceito, após revisão, em 24/11/2003.
Durante as décadas de 70 e 80 , a artrografia, introduzida por Norgaard, em 1940, era considerada o método de primeira escolha para a visualização dos deslocamentos de disco da $\mathrm{ATM}^{(2)}$. A morfologia, o posicionamento e a função do disco articular eram visualizados, de forma indireta, em função da injeção de meio de contraste nos compartimentos articulares superior e/ou inferior. Após a injeção do contraste, imagens videofluoroscópicas dinâmicas eram obtidas, com movimento de abertura e fechamento da boca. Apesar de válida na identificação de problemas como as perfurações de disco, a artrografia não é muito recomendada, atualmente, uma vez que é técnica invasiva que envolve dose de radiação ionizante relativamente alta e causa desconforto ao paciente ${ }^{(3-5)}$.

$\mathrm{O}$ exame por ressonância magnética (RM), introduzido em meados dos anos 80, tornou-se o método de primeira escolha para o diagnóstico das anormalidades dos tecidos moles da ATM, devido à alta acurácia na determinação da posição do disco articular. É o único exame capaz de apresentar a imagem do disco articular, possibilitando, dessa forma, o diagnóstico dos seus deslocamentos ${ }^{(2,6)}$. Possibilita, ainda, informações a respeito da condição óssea (cortical e medular) ${ }^{(7)}$, degenerações discais, quantidade de fluido sinovial e dos tecidos retrodiscais ${ }^{(8)}$.

Método avançado e não-invasivo, a RM geralmente é bem tolerada pelo paciente e é de fácil execução, quando comparada à artrografia. Além disso, apresenta a grande vantagem de não expor o paciente à radiação ionizante, para a obtenção das imagens.

O objetivo deste trabalho é realizar uma revisão de literatura, abordando os aspectos normais e os diferentes tipos de deslocamentos de disco da ATM à RM.

\section{ANATOMIA DA ATM}

A articulação da mandíbula com o crânio é do tipo sinovial móvel composta ${ }^{(9)}$. Em virtude da sua forma de dobradiça 
(ginglymus) e sua função de deslizamento (arthrodia), também é denominada de articulação ginglemoartroidal ${ }^{(\mathbf{9 , 1 0})}$.

Em geral, a ATM, referida como a articulação mais complexa do organismo humano, apresenta como componentes ósseos a fossa articular, que faz parte da porção escamosa do osso temporal, e o côndilo da mandíbula, localizado no topo do pescoço condilar ${ }^{(\mathbf{1}, \mathbf{1 0})}$.

O disco articular é uma estrutura bicôncava, flexível, formado por tecido conjuntivo fibroso denso, normalmente situado entre o declive posterior da eminência articular e a superfície ântero-superior do côndilo, dividindo o espaço articular em dois compartimentos, superior e inferior. Em condições de normalidade, estes compartimentos não se comunicam ${ }^{(\mathbf{1}, 9,11)}$. O disco possui uma banda posterior, uma zona intermediária e uma banda anterior. Sua zona intermediária é consideravelmente mais fina do que a periferia, sendo sua banda posterior mais espessa ${ }^{(\mathbf{1 , 9 , 1 0 )}}$.

A posição normal do disco articular da ATM, em boca fechada, é aquela em que se tem um alinhamento entre o ponto médio do contorno superior do côndilo da mandíbula e o limite distal da banda posterior do disco (posição de 12 horas) (Figura 1A). No entanto, nem todas as articulações exibem esta posição, existindo também variações da normalidade, que podem ser observadas quando a proeminência anterior do côndilo encontra-se à mesma altura e na vizinhança da zona intermediária do disco. Um leve deslocamento da zona intermediária para anterior é considerado deslocamento do disco articular. Em posição de abertura máxima da boca, o disco normalmente encontra-se posicionado entre a superfície póstero-superior do côndilo e a superfície convexa do tubérculo do osso temporal (Figura 1B) $)^{(11,12)}$.

\section{DESLOCAMENTOS DE DISCO DA ATM}

O deslocamento de disco da ATM tem sido definido como uma relação anormal do disco articular com o côndilo mandibular, fossa e eminência articulares ${ }^{(13)}$. É válido salientar que os deslocamentos de disco também podem estar presentes sem causar sintomas e sem interferir com a função
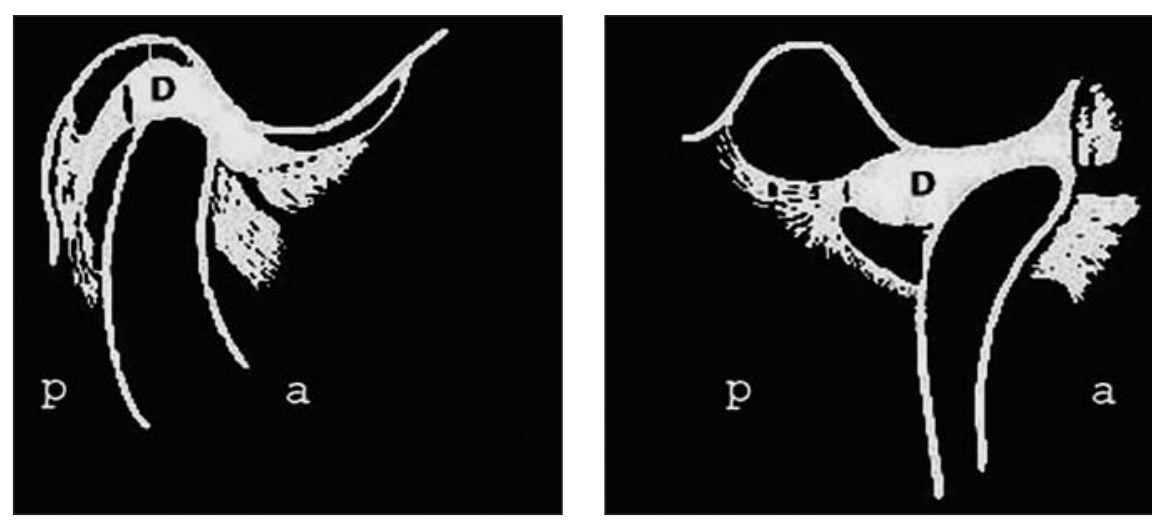

A

Figura 1. Representação esquemática da ATM, no plano sagital, em posição de boca fechada (A) e aberta (B), com o disco articular (D) em posição normal. (a, porção anterior da ATM; p, porção posterior da ATM).

articular a curto prazo. As aderências, corpos livres intra-articulares, doenças articulares inflamatórias e degenerativas, sem associação com deslocamento de disco, também podem causar distúrbios intra-articulares (DIA) ${ }^{(\mathbf{1 1})}$. Dos DIA, o deslocamento do disco articular é o mais comumente encontrado ${ }^{(4)}$.

Sinais e sintomas associados a DIA da ATM são comuns, ocorrendo em $4 \%$ a $28 \%$ da população adulta ${ }^{(4)}$. Foi demonstrado que os DIA, assim como a artrite degenerativa, podem acometer pacientes pediátricos $^{(\mathbf{1 4})}$. Os DIA incidem mais freqüentemente nas mulheres, ocorrendo numa proporção aproximada de $8: 1$, sendo que os fatores responsáveis por esta predominância ainda não estão claros. Fatores etiológicos relacionados aos DIA da ATM incluem trauma, bruxismo, estresse e anormalidades oclusais. Em estudo realizado com 192 ATM de 98 pacientes sintomáticos que realizaram RM desta articulação, cerca de $80 \%$ dos pacientes da amostra apresentaram deslocamento de disco bilateral, $15 \%$ mostraram deslocamento de disco unilateral e somente $5 \%$ dos pacientes apresentaram ATM normais ${ }^{(8)}$. A prevalência de deslocamentos de disco encontrada por outros autores em voluntários assintomáticos foi de $33 \%$ e de $77 \%$ em pacientes sintomáticos ${ }^{(\mathbf{1 5})}$.

Os deslocamentos de disco totalizam oito posições anômalas, entre elas: deslocamento anterior completo, deslocamento anterior parcial lateral, deslocamento anterior parcial medial, deslocamento rotacional ântero-medial, deslocamento rotacio- nal ântero-lateral, deslocamento medial, deslocamento lateral, e deslocamento posterior, este último bastante raro ${ }^{(8)}$.

O deslocamento anterior do disco articular da ATM é o mais freqüentemente encontrado $^{(8,12)}$. Pode ser completo ou parcial, dependendo da extensão do deslocamento $^{(\mathbf{8}, 11)}$. Em posição de boca fechada, o disco apresenta-se posicionado anteriormente em todos os cortes sagitais. Os deslocamentos medial e lateral do disco articular possuem aspecto normal nos cortes sagitais em boca fechada, porém apresentam alteração da posição do disco no plano coronal ${ }^{(\mathbf{8})}$. Estes deslocamentos são freqüentemente associados ao deslocamento anterior, sendo denominados de deslocamentos rotacionais do disco ${ }^{(\mathbf{1 1})}$.

Os deslocamentos discais podem ocorrer com ou sem redução, excetuando-se o deslocamento posterior. Esta classificação depende do reestabelecimento ou não da relação normal entre o disco articular e o côndilo mandibular, no movimento de abertura da boca. Quando o disco permanece deslocado na posição de abertura máxima da boca, considera-se deslocamento sem redução (Figura 2). No entanto, quando o disco é recapturado para a posição de normalidade em boca aberta, dizse que o deslocamento é com redução ${ }^{(\mathbf{1 6})}$ (Figura 3). Redução incompleta é vista quando há recaptura parcial do disco articular durante a abertura da boca ${ }^{(8)}$.

Os deslocamentos de disco da ATM são considerados uma importante causa da dor facial, da ATM, de estalidos, crepitação e disfunção ${ }^{(17)}$. Os deslocamentos de disco 


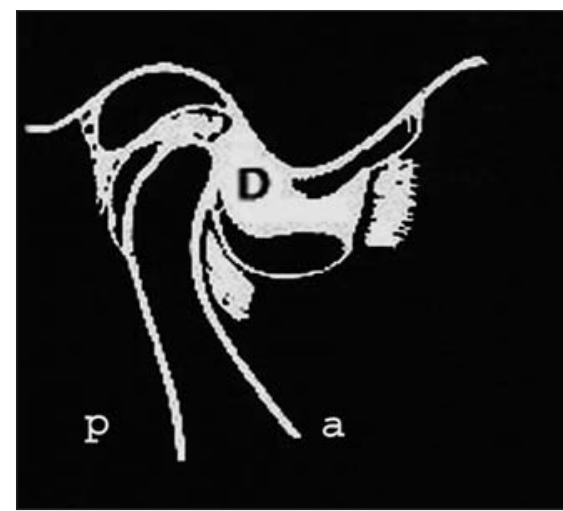

A

Figura 2. Representação esquemática da ATM, no plano sagital, em posição de boca fechada (A) e aberta (B), exibindo deslocamento anterior do disco articular (D) sem redução. No final do movimento de abertura da boca, o disco continua deslocado anteriormente. (a, porção anterior da ATM; p, porção posterior da ATM).
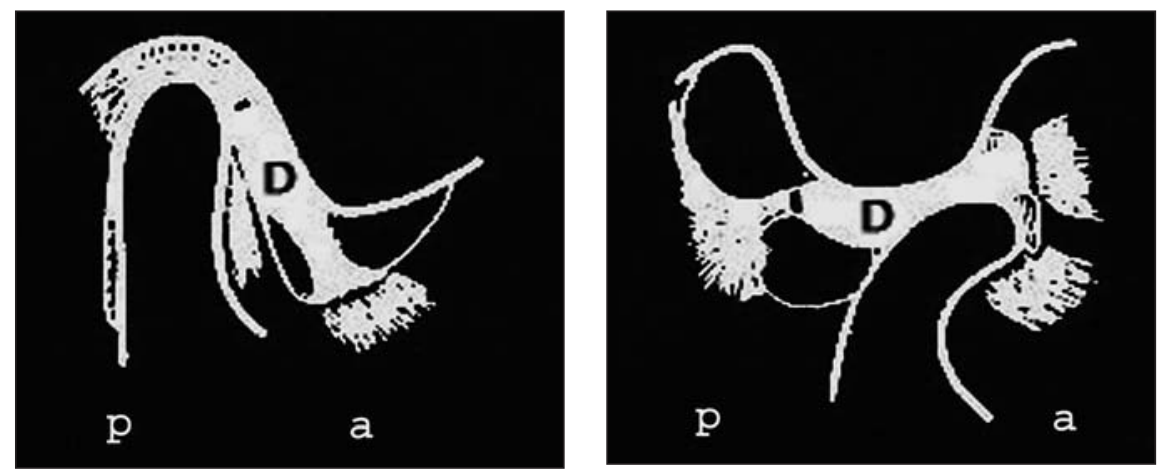

A

B

Figura 3. Representação esquemática da ATM, no plano sagital, em posição de boca fechada (A) e aberta (B), exibindo deslocamento anterior do disco articular (D) com redução. No final do movimento de abertura da boca, o disco é recapturado para a posição de normalidade. (a, porção anterior da ATM; p, porção posterior da ATM).

com redução estão freqüentemente associados a estalidos, e os deslocamentos de disco sem redução apresentam-se mais freqüentemente associados à limitação da abertura da boca ${ }^{(5,17)}$.

Alterações estruturais ósseas, como erosão, facetamento, formação de osteófitos e esclerose, ocorrem mais freqüentemente em pacientes com deslocamentos anteriores do disco articular sem redução e raramente em pacientes com deslocamento de disco com redução. Estas alterações acometem predominantemente pacientes com DIA em estágio avançado e podem ser interpretados como sinais de progressão da doença ${ }^{(18)}$.

\section{DIAGNÓSTICO POR IMAGEM}

Várias técnicas de imagem para a ATM têm sido discutidas, focalizando suas indi- cações e limitações ${ }^{(\mathbf{1 9 )}}$. A artrografia já foi amplamente usada no passado como método de diagnóstico por imagem para ATM com DIA, porém, atualmente, sua utilização não é indicada, pois é procedimento invasivo que causa desconforto e riscos. Reações alérgicas ao meio de contraste, apesar de raras, podem ocorrer. Além disso, a exposição à radiação pode ser significativa, dependendo do número de exposições tomográficas. Perfurações do disco e laceração da cápsula são, contudo, melhor detectados pela artrografia ${ }^{(\mathbf{1 9})}$.

Apesar do uso da radiação ionizante, a tomografia computadorizada (TC) pode fornecer informações importantes quando se necessita de detalhes de toda a anatomia óssea. Apresenta, adicionalmente, a vantagem das reconstruções tridimensionais, que são úteis na avaliação das deformidades ósseas $^{(4)}$.
A RM é o exame de eleição para o estudo da ATM quando se deseja pesquisar anormalidades de tecidos moles. É o único exame que possibilita a visualização do disco articular e tecidos moles circunjacentes. Informações a respeito do contorno ósseo cortical também são obtidas por meio do exame de RM. Além disso, anormalidades na intimidade da medula óssea do côndilo também podem ser evidenciadas. É uma técnica não-invasiva que, apesar do custo elevado, fornece uma série de informações referentes às estruturas intraarticulares, em diversos planos ${ }^{(\mathbf{1 9})}$. Uma vez que a RM apresenta alta acurácia na identificação das posições do disco da ATM, além das vantagens já referidas, Tasaki et $a l .^{(\mathbf{1 2})}$ e Emshoff e Rudisch ${ }^{(\mathbf{2 0})}$ relataram que a RM deveria ser reconhecida como padrão-ouro para propósitos de identificação da posição do disco articular da ATM.

Para pacientes que apresentam sinais e sintomas de dor articular e/ou facial, estalidos, crepitação e limitação da abertura da boca associados à ATM e que, ao exame físico, suspeita-se de DIA por interferência do disco, a RM é indicada como método de escolha. Exames para avaliação óssea, como radiografias ou TC, também podem ser indicados, principalmente quando se suspeita de deslocamento crônico de $\operatorname{disco}^{(\mathbf{1 9})}$.

\section{A IMAGEM DA ATM POR RM}

Os protocolos utilizados para a obtenção das seqüências de imagens da ATM ponderadas em T1 (sagitais, em boca fechada e aberta, com cortes de $2 \mathrm{~mm}$ de espessura) e em densidade de prótons (coronais, em boca fechada, com cortes de $2 \mathrm{~mm}$ de espessura) estão descritos na Tabela 1 (adaptado de Katzberg e Westesson ${ }^{(11)}$ ). As seqüências de imagens ponderadas em T1 são utilizadas rotineiramente ${ }^{(7,8,11)}$, fornecendo excelente detalhamento anatômico. As sequiências de imagens ponderadas em densidade de prótons também fazem parte do protocolo de rotina, uma vez que apresentam boa resolução espacial nas lesões do disco articular, além de ser excelente opção na individualização dos deslocamentos discais lateral e medial. As imagens ponderadas em T2, no entanto, fornecem pobre detalhe anatômico, sendo 
Tabela 1 Protocolo de rotina para a obtenção de seqüências de imagens da ATM em T1 e em densidade de prótons (adequado de Katzberg e Westesson ${ }^{(11)}$ ).

\begin{tabular}{|l|c|c|c|c|c|c|}
\hline \multicolumn{1}{|c|}{ Imagem } & $\begin{array}{c}\text { TR } \\
(\mathrm{ms})\end{array}$ & $\begin{array}{c}\text { TE } \\
(\mathrm{ms})\end{array}$ & NEX & $\begin{array}{c}\text { FOV } \\
(\mathrm{cm})\end{array}$ & $\begin{array}{c}\text { Espessura } \\
\text { de corte } \\
(\mathrm{mm})\end{array}$ & Matriz \\
\hline Localizadora axial (boca fechada) & 400 & 13 & 1 & 20 & 4 & $256 \times 256$ \\
Sagital T1 (boca fechada) & 450 & 13 & 5 & 14 & 2 & $256 \times 256$ \\
Sagital T1 (boca aberta) & 450 & 13 & 5 & 14 & 2 & $256 \times 256$ \\
Coronal DP (boca fechada) & 1.750 & 17 & 5 & 12 & 2 & $256 \times 256$ \\
\hline
\end{tabular}

TR, tempo de repetição; TE, tempo de eco; NEX, número de excitações; FOV, campo de visão ("field of view"); DP, densidade de prótons.

indicadas quando se deseja acentuar a efusão articular e o edema na medula óssea ${ }^{(11)}$. A aquisição adicional das seqüências de imagens ponderadas em T2 é realizada em pequeno número de situações clínicas, como em casos pós-traumatismo ou tumefação na região periauricular ${ }^{(21)}$. Segundo Pieruci et $a l .{ }^{(21)}$, apesar de as imagens ponderadas em T2 permitirem uma melhor apreciação do estado do disco articular e da presença de líquido intra-articular ou de aderências, estas informações têm hoje pequeno valor no momento da decisão terapêutica.

Um exame de RM da ATM normal demonstra o disco articular como uma estrutura de intensidade de sinal baixa, situado entre o côndilo e a fossa articular, normalmente descrito em forma de "gravata bor-

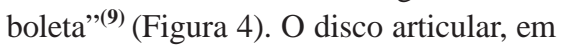
imagens ponderadas em $\mathrm{T} 1$, aparece em hipossinal, o que é explicado pela sua ri- queza em proteoglicanas. A forma de "gravata borboleta" não é identificada sempre, em razão do efeito de volume parcial, cortes oblíquos, espessura do corte e tamanho e morfologia do disco ${ }^{(9)}$. A combinação das sequiências em posição de boca aberta e boca fechada, porém, sempre auxilia na diferenciação da posição do disco normal

Existem situações em que se observa uma pequena área de sinal intenso no interior da banda posterior do disco. $\mathrm{O}$ aumento de sinal é decorrente de depósitos de mucina na região do tecido discal. Esta alteração pode ser vista tanto em articulações normais quanto em anormais ${ }^{(\mathbf{1 1 1})}$.

O tecido retrodiscal é uma estrutura fina, possuindo intensidade de sinal homogênea intermediária na posição de boca fechada. Em alguns casos, o tecido não pode ser identificado claramente em razão da justaposição deste com o complexo fie anormal ${ }^{(5,9)}$.

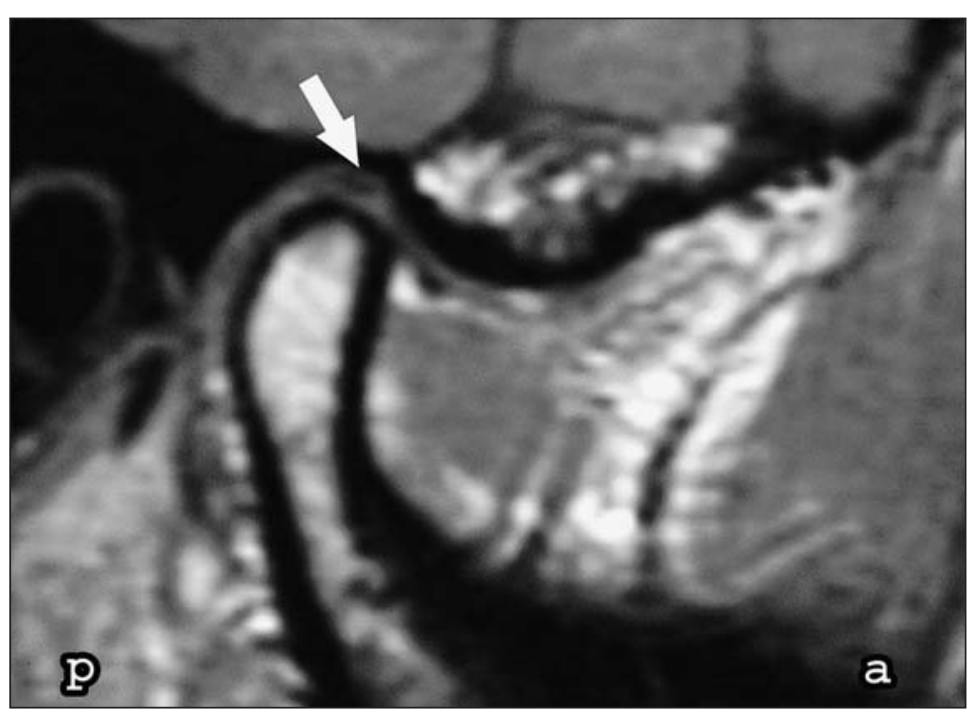

Figura 4. RM da ATM, ponderada em T1, corte sagital, em boca fechada, lado direito. Observa-se o disco articular, em hipossinal, posicionado entre o côndilo e a fossa articular, em posição de normalidade e em forma de "gravata borboleta" (seta). (a, porção anterior da ATM; p, porção posterior da ATM). brocartilagem-camada sinovial-osso cortical da fossa articular e do côndilo ${ }^{(9)}$. Na posição de boca aberta, o tecido retrodiscal se expande para baixo da concavidade da fossa articular e pode demonstrar intensidade de sinal heterogênea. A heterogeneidade ocorre em razão do fluxo de sangue para dentro desta região durante a abertura da boca ${ }^{(9,11)}$.

A inserção do feixe superior do músculo pterigóideo lateral é freqüentemente demonstrada através de imagem por RM como uma estrutura em hipossinal, que se insere no aspecto ântero-medial do disco e côndilo ${ }^{(11)}$. Os dois feixes do músculo pterigóideo lateral aparecem normalmente separados por uma região adiposa, triangular, de sinal intenso ${ }^{(21)}$.

A fibrocartilagem que recobre a fossa articular e a eminência articular aparece com sinal de intensidade intermediária, separando o sinal de baixa intensidade do córtex do osso temporal, do disco articular. Esta camada de tecido que recobre o côndilo nem sempre é aparente. Existe uma tendência errônea de assumir que a pequena intensidade de sinal do córtex do côndilo se articula diretamente com o tecido discal. Esta camada se torna mais evidente quando o disco deslocado está acompanhado de remodelação condilar significativa ${ }^{(9)}$.

Com a melhora na qualidade das imagens por RM, a cápsula articular freqüentemente é bem visualizada nas imagens coronais. Em articulações normais, a cápsula é vista como uma linha escura, relativamente plana e fina, localizada lateralmente ao côndilo. Em articulações com deslocamentos laterais do disco, é comum observar o seu espessamento. Em pacientes com edema e dor na região articular, imagens ponderadas em T2, no plano coronal, têm mostrado aumento de fluido na cápsula articular, sugestivo de edema capsular. Todas estas observações são sugestivas de capsulite ${ }^{(\mathbf{1 1})}$.

Nos diferentes tipos de deslocamentos, o disco se apresenta com a mesma intensidade de sinal descrita acima. A diferença é o seu posicionamento, como já descrito (Figuras 5 e 6). Uma série de alterações na configuração do disco também pode ser encontrada em pacientes com DIA da ATM. Em geral, o primeiro estágio de deformação é o espessamento da banda pos- 


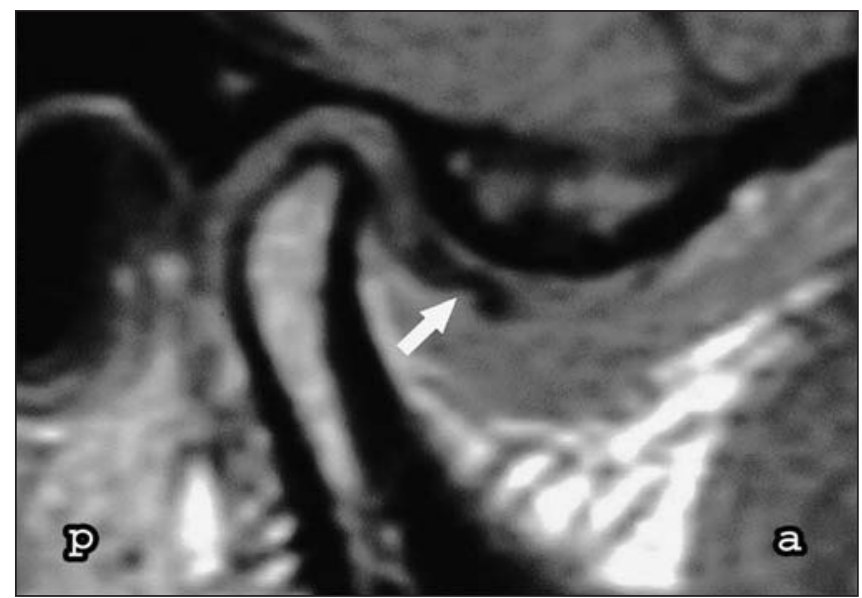

A

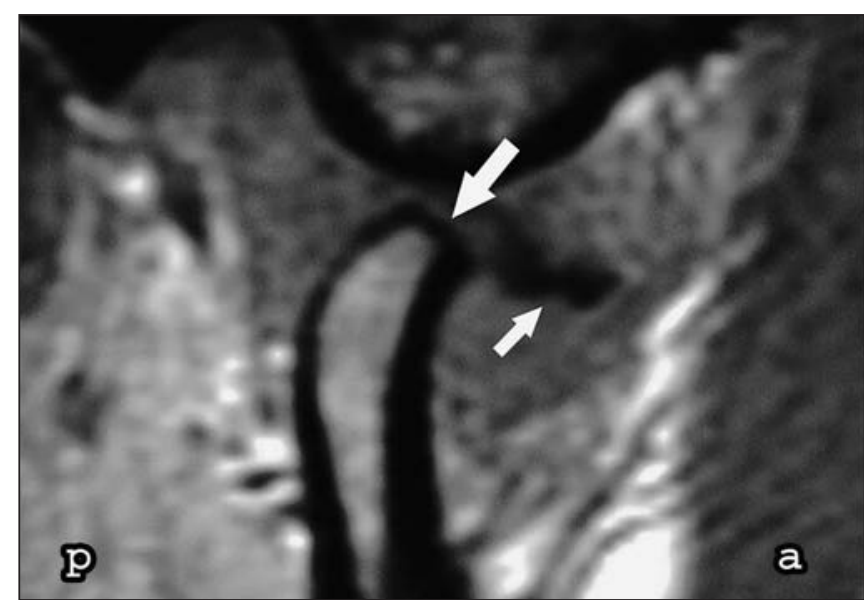

Figura 5. A: RM da ATM, ponderada em T1, corte sagital, em boca fechada, lado direito. 0 disco articular, em hipossinal, apresenta deformação e deslocamento anterior total (seta). B: RM da ATM, ponderada em T1, corte sagital, em boca aberta, lado direito. Após o movimento de abertura da boca, o disco articular continua deslocado anteriormente (seta menor). Observa-se deslocamento anterior do disco sem redução. A porção ântero-superior do côndilo encontra-se levemente facetada (seta maior). (a, porção anterior da ATM; p, porção posterior da ATM).

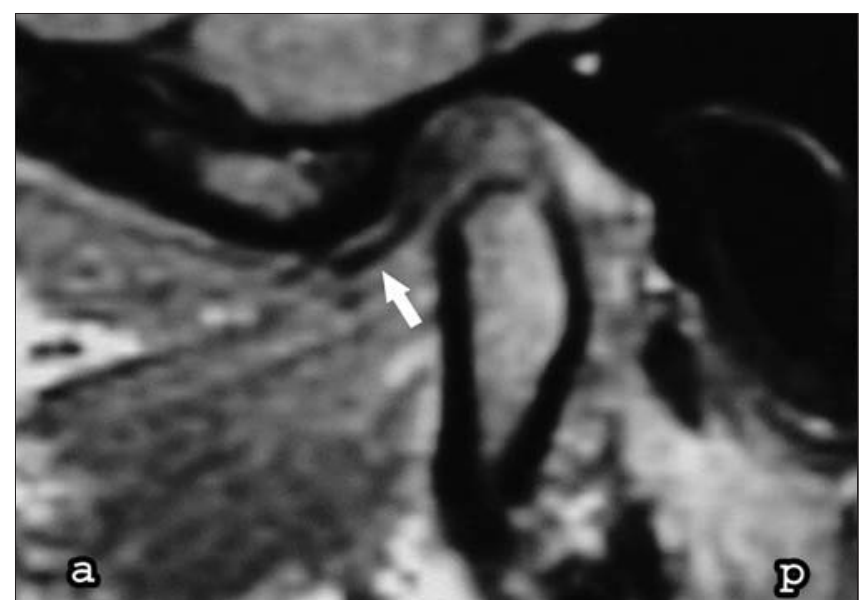

A

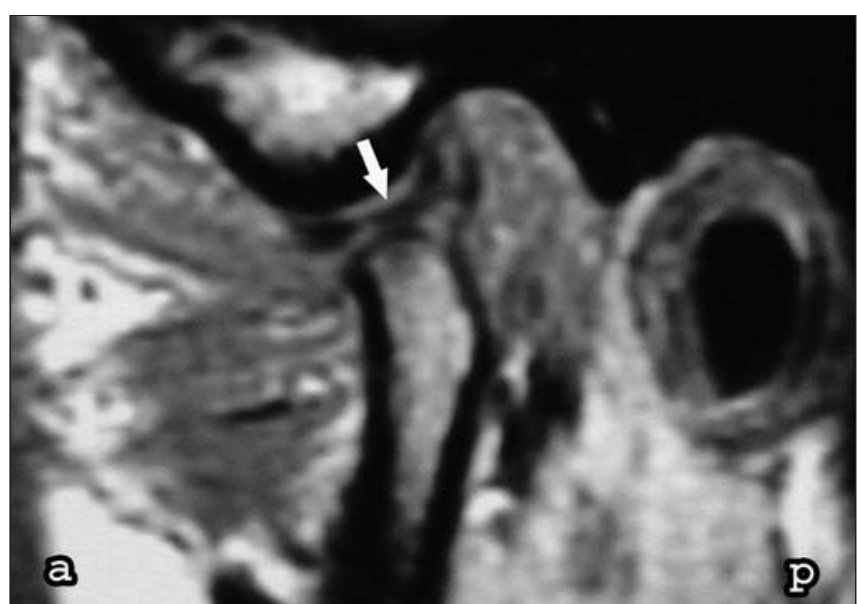

B

Figura 6. A: RM da ATM ponderada em T1, corte sagital, em boca fechada, lado esquerdo. 0 disco articular, em hipossinal, apresenta deslocamento anterior parcial (seta). B: RM da ATM ponderada em T1, corte sagital, em boca aberta, lado esquerdo. Após o movimento de abertura da boca, o disco articular foi recapturado para a posição de normalidade (seta). Observa-se deslocamento anterior parcial do disco articular, com redução. (a, porção anterior da ATM; p, porção posterior da ATM).

terior do disco articular (Figura 7). A etapa seguinte é quando a banda posterior aumenta em espessura e em comprimento ântero-posterior, resultando em uma forma biconvexa. Com a posição de boca aberta, a configuração é arredondada. Uma configuração sigmóide também é possível de ser observada ${ }^{(\mathbf{1 1})}$.

Os deslocamentos mediais ou laterais do disco articular são identificados melhor no plano coronal ${ }^{(5)}$ (Figura 8).

Nas articulações com deslocamentos crônicos e deformações de disco, é comum encontrar alterações em tecido ósseo, que podem ser vistas não somente no contor- no das superfícies articulares, como também na intensidade do sinal da medula óssea adjacente. As alterações medulares são comumente associadas aos DIA crônicos e podem ser vistas na presença ou na ausência de alterações morfológicas da cortical $^{(11)}$. Em condições de normalidade, a cortical óssea mostra ausência de sinal e a medular apresenta sinal elevado ${ }^{(21)}$.

Edema na medula óssea também pode ser observado através de imagens por RM, como hipersinal em imagens ponderadas em T2. Esta situação não é encontrada em pacientes com ATM normais, nem em pacientes com DIA assintomáticos ${ }^{(\mathbf{1 1})}$.
A efusão articular, mais comumente encontrada em pacientes que apresentam deslocamentos de disco em estágios avançados, é identificada, na imagem por RM, como uma área de intensidade de sinal elevado, na região dos espaços articulares, em imagens ponderadas em T2. Quando não existe nenhuma área de sinal elevado ou quando existe somente a presença de uma linha de sinal elevado ao longo da superfície articular, considera-se ausência de efusão $\operatorname{articular}^{(22)}$.

Uma limitação da RM é a inabilidade de demonstrar perfurações de disco ${ }^{(\mathbf{1 1}, 21)}$. No entanto, o contato de osso com osso 


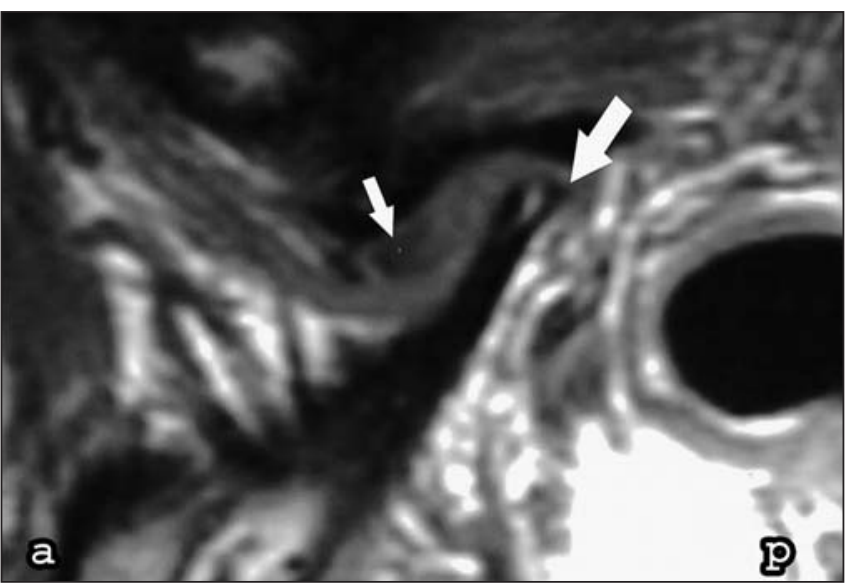

Figura 7. RM da ATM ponderada em T1, corte sagital, em boca fechada, lado esquerdo. 0 disco articular, em hipossinal, acha-se deslocado anteriormente (seta menor), com sua banda posterior espessada e localizada anteriormente ao côndilo hipoplásico (seta maior). (a, porção anterior da ATM; b, porção posterior da ATM).

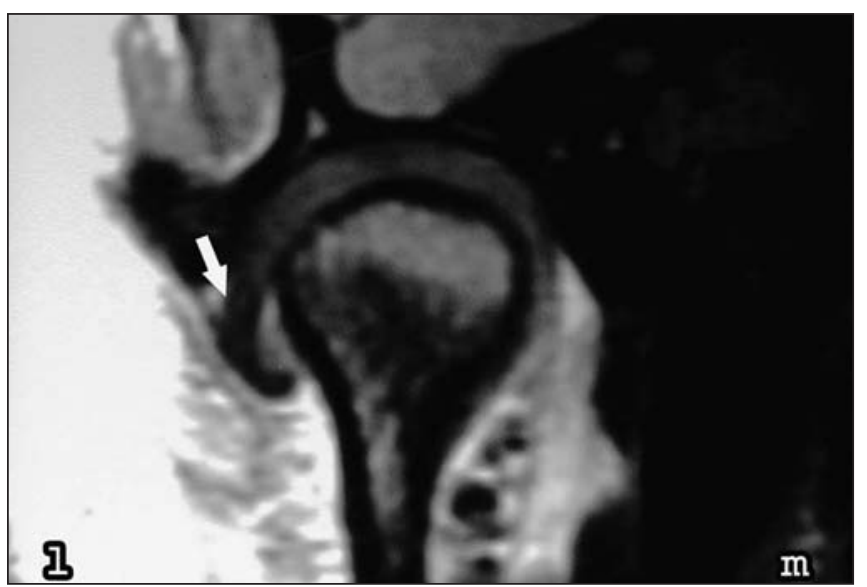

Figura 8. RM da ATM, em densidade de prótons, corte coronal, em boca fechada, lado direito. Disco articular, em hipossinal, encontra-se com deslocamento lateral (seta). (I, porção lateral da ATM; m, porção medial da ATM). (côndilo mandibular com a porção escamosa do osso temporal), associado a doença articular degenerativa, é sinal indireto de perfuração discal à RM. Ocasionalmente, com imagens ponderadas em T2 e na presença de efusão articular, é possível demonstrar a presença de perfurações no ligamento posterior do disco. Apesar da constante preocupação no diagnóstico das perfurações de disco, esta não é a característica principal de um DIA. O deslocamento e/ou deformação do disco são os maiores parâmetros que determinam a conduta terapêutica ${ }^{(\mathbf{1 1})}$.

A RM tem assumido importância fundamental no campo da odontologia, neste caso, especificamente, no diagnóstico por imagem dos diferentes tipos de deslocamentos do disco articular da ATM. O diagnóstico correto é necessário para um planejamento de tratamento adequado.

\section{Agradecimentos}

Este trabalho recebeu o apoio da Clínica Delfin Médica e Odontológica e da Fundação de Amparo à Pesquisa do Estado da Bahia (Fapesb).

\section{REFERÊNCIAS}

1. Maciel RN, Turell JCF. Anatomia da ATM. In: Maciel RN, Westesson PL, Turell JCF, et al. ATM e dores craniofaciais - fisiopatologia básica. $1^{\underline{a}}$ ed. São Paulo, SP: Livraria Editora Santos, 2003:6390.

2. Sano T. Recent developments in understanding temporomandibular joint disorders. Part 1: bone mar- row abnormalities of the mandibular condyle. Dentomaxillofac Radiol 2000;29:7-10.

3. Gonini Júnior A, Tanaka EE, Arita ES. Recursos e métodos para a visualização das disfunções temporomandibulares quanto ao comprometimento extra e intra-articular. RPG Rev Pós Grad 1999;6: 262-8.

4. Katzberg RW. Temporomandibular joint imaging. Radiology 1989;170:297-307.

5. Maciel RN, Tavano O, Bueno MR. Imagens: protocolo radiográfico. In: Maciel RN, Westesson PL, Turell JCF, et al. ATM e dores craniofaciais - fisiopatologia básica. 1ª ed. São Paulo, SP: Livraria Editora Santos, 2003:239-92.

6. Reis RH, Armond MC, Carlos RG, Ribeiro A. Tomografia computadorizada e ressonância magnética no diagnóstico das disfunções da ATM. Rev Univ Vale do Rio Verde 1998;1:119-24.

7. Nebbe B, Brooks SL, Hatcher D, et al. Magnetic resonance imaging of the temporomandibular joint: interobserver agreement in subjective classification of disk status. Oral Surg Oral Med Oral Pathol Oral Radiol Endod 2000;90:102-7.

8. Milano V, Desiate A, Bellino R, Garofalo T. Magnetic resonance imaging of temporomandibular disorders: classification, prevalence and interpretation of disc displacement and deformation. Dentomaxillofac Radiol 2000;29:352-61.

9. Heffez LB, Mafee MF, Rosenberg HM. Imaging atlas of the temporomandibular joint. 1st ed. Philadelphia, PA: Williams \& Wilkins, 1995.

10. Okeson JP. Tratamento das desordens temporomandibulares e oclusão. 4ํe ed. São Paulo, SP: Artes Médicas, 2000.

11. Katzberg RW, Westesson PL. Diagnosis of the temporomandibular joint. Philadelphia, PA: WB Saunders, 1993.

12. Tasaki MM, Westesson PL, Isberg AM, Ren YF, Tallents RH. Classification and prevalence of temporomandibular joint disk displacement in patients and symptom-free volunteers. Am J Orthod Dentofacial Orthop 1996;109:249-62.

13. Tallents RH, Katzberg RW, Murphy W, Proskin H. Magnetic resonance imaging findings in asymptom- atic volunteers and symptomatic patients with temporomandibular disorders. J Prosthet Dent 1996; 75:529-33.

14. Sanchez-Woodworth RE, Katzberg RW, Tallents RH, Guay JA. Radiographic assessment of temporomandibular joint pain and dysfunction in the pediatric age-group. ASDC J Dent Child 1988;55: 278-81.

15. Katzberg RW, Westesson PL, Tallents RH, Drake CM. Orthodontics and temporomandibular joint internal derangement. Am J Orthod Dentofacial Orthop 1996;109:515-20.

16. Kurita H, Ohtsuka A, Kobayashi H, Kurashina K The relationship between the degree of disk displacement and ability to perform disk reduction. Oral Surg Oral Med Oral Pathol Oral Radiol Endod 2000;90:16-20.

17. Katzberg RW, Westesson PL, Tallents RH, Drake $\mathrm{CM}$. Anatomic disorders of the temporomandibular joint disc in asymptomatic subjects. J Oral Maxillofac Surg 1996;54:147-53.

18. Westesson PL. Structural hard-tissue changes in temporomandibular joints with internal derangement. Oral Surg Oral Med Oral Pathol 1985;59: 220-4.

19. Brooks SL, Brand JW, Gibbs SJ, et al. Imaging of the temporomandibular joint: a position paper of the American Academy of Oral and Maxillofacial Radiology. Oral Surg Oral Med Oral Pathol Oral Radiol Endod 1997;83:609-18.

20. Emshoff R, Rudisch A. Validity of clinical diagnostic criteria for temporomandibular disorders: clinical versus magnetic resonance imaging diagnosis of temporomandibular joint internal derangement and osteoarthrosis. Oral Surg Oral Med Oral Pathol Oral Radiol Endod 2001;91:50-5.

21. Pieruci P, Chassagne JF, Briche D, Dinh Doan G L'intérêt de l'IRM dans la visualisation du ménisque des articulations temporo-mandibulaires (ATM). Rev Stomatol Chir Maxillofac 1991;92:149-54.

22. Westesson PL, Brooks SL. Temporomandibular joint: relationship between MR evidence of effusion and the presence of pain and disk displacement. AJR 1992;159:559-63. 